\title{
How Fiscal Space Matters? Evidence on Fiscal Multipliers from Threshold SVAR Methodology ${ }^{1}$
}

\author{
Martin KAMENIK* ${ }^{*}$ Lubica STIBLAROVA**
}

\begin{abstract}
In this paper, we alternatively apply a threshold SVAR methodology to measure fiscal multipliers in selected world's economies with regard to the size of the fiscal space defined by a proxy variable of primary balance, which may be substantially linked to the ability of the fiscal policy instruments to affect the output. Results suggest that positive and negative shocks do not necessarily result in symmetric response of variables as smaller fiscal multipliers (i.e., less effective fiscal policies) are observed when economies show weaker fiscal position. Thus, expansionary fiscal policy in times of narrow fiscal space dampens expansionary effects on real economic activity. At the same time, we find considerably lower revenue than spending multipliers, confirming Keynesian theory (except for France).
\end{abstract}

Keywords: fiscal multiplier, government spending, threshold SVAR model, fiscal shock

JEL Classification: C32, E62, H50, H60

DOI: https://doi.org/10.31577/ekoncas.2021.04.01

\section{Introduction}

The post-Great Recession period has highlighted the role of the fiscal policy in the stabilization of the economy, but also raised many doubts about its effectiveness, mainly in relation to more intensive use of the fiscal stimuli in recent years (e.g., Coelho, 2019). Are large fiscal stimulus packages - for instance, widely used by the US active fiscal policy, providing satisfactory countercyclical

\footnotetext{
* Martin KAMENIK, Technical University of Košice, Faculty of Economics, Department of Economic Theories, Němcovej 32, 04001 Košice, Slovak Republic; e-mail: martinkamenik3@ gmail.com

** Lubica STIBLAROVA, Technical University of Košice, Faculty of Economics, Department of Finance, Němcovej 32, 04001 Košice, Slovak Republic; e-mail: lubica.stiblarova@ tuke.sk

${ }^{1}$ This work was supported by the Scientific Grant Agency VEGA under Grant No. 1/0394/21.
} 
impulse in the recessionary periods $?^{2}$ The academics and the policymakers tend to find the answer to this question, broadening discussions on the fiscal policy transmission and its effects on real economy (e.g., Barro and Redlick, 2011; Baum and Koester, 2011; Auerbach and Gorodnichenko, 2012; Ilzetzki, Mendoza and Vegh, 2013; Dupor and Guerrero, 2017).

The fiscal multiplier, i.e., the ratio of change in the output to a discretionary change in government spending or tax revenue (Spilimbergo, Symansky and Schindler, 2009), has received substantial theoretical and empirical attention in this context.

However, there is still little consensus in the literature on the size of the multipliers, which might come from diverse estimation approaches (Nakamura and Steinsson, 2014) or the obstacles related to the contemporaneous effects of the fiscal and the monetary policy instruments (Coelho, 2019). In particular, the fiscal policy instruments such as changes in government spending or taxes are endogenous to the output fluctuations either due to automatic stabilizers or discretionary policy (Perotti, 2004; Barro and Redlick, 2011), which forces economists to choose among the structural vector autoregressive (SVAR) models, the dynamic stochastic general equilibrium (DSGE) models, the narrative approach, and the instrumental approach. Among these, the SVAR identification strategy à la Blanchard and Perotti (2002) has been the most widely applied technique for the estimation of the country-specific fiscal multipliers (see, e.g., Blanchard and Perotti, 2002; Perotti, 2004; Ilzetzki, Mendoza and Vegh, 2013).

In spite of the fact that these models have become an increasingly popular tool for studying transmission mechanisms of the fiscal policy, traditional linear SVAR models are unable to detect nonlinear effects related to the fiscal multipliers, which can be present and thus, limit such empirical findings. A perfect example, where nonlinearities should be taken into account, is the issue of the narrow or wide fiscal space, i.e., the availability of the budgetary resources for a specific purpose without jeopardizing the sustainability of the government's financial position or the sustainability of the economy (Ley, 2009), which may be substantially linked to the ability of the fiscal policy instruments to affect the output.

In theory, a size of the fiscal space may affect fiscal adjustment through two channels; the Ricardian channel, which operates through households and the interest rate channel, determined by the investors' behavior (Perotti, 1999; Corsetti, Meier and Muller, 2012). When government pursues active fiscal policy through government stimuli in case of narrow fiscal space, the Ricardian channel implies that households anticipate tax increases, which means that instead of increasing

\footnotetext{
${ }^{2}$ So-called, the American Recovery and Reinvestment Act (ARRA) in 2009 of approx. 800 billion USD.
} 
consumption, they pre-emptively increase savings, dampening private consumption (Perotti, 1999; Huidrom et al., 2019). Such active fiscal policy is often followed by the fiscal contraction as anticipating economic subjects reduce the effects of the fiscal expansion (Ilzetzki, Mendoza and Vegh, 2013). Alternatively, the interest rate channel implies that limited fiscal space raises borrowing costs through higher sovereign bond yields responding to the investors' concerns. This, inter alia, increases economy-wide borrowing cost and dampens expansionary effects of the fiscal policy on the private investment (Corsetti, Meier and Muller, 2012).

Although a theory offers explanations of potential linkages between fiscal space and fiscal policy effectiveness, practical assessment of fiscal space faces many challenges; fiscal space presents a complex concept, with no single definition so far (Kose et al., 2017; Cheng and Pitterle, 2018), whereas various measures of fiscal space emphasize different aspect of the fiscal space concept (Cheng and Pitterle, 2018). Moreover, the role of the fiscal space with regard to the size of the fiscal multipliers (i.e., its nonlinear effects) has been scarcely examined in the empirical literature so far. Rare examples present studies of Auerbach and Gorodnichenko (2012) or Ilzetzki, Mendoza and Vegh (2013), whereas the Ricardian and the interest rate channels have not been properly examined until very recent study of Huidrom et al. (2019). ${ }^{3}$

Nevertheless, one of the crucial shortcomings of these studies is that they are uniformly focused only on one indicator - a debt-to-GDP ratio, with a lack of any other indicators of fiscal space. A higher debt-to-GDP ratio can be associated with more volatile economic growth, which can lead to less effective fiscal policy in boosting economic activity during recessions; many authors underline a particular debt-to-GDP threshold (mostly around 90 percent of GDP), above which an increase of a debt level has negative effects on economic growth (see, e.g., Reinhart and Rogoff, 2010). Although, more recent studies call attention to sensitivity in previous studies' modelling choices and data coverage (see, e.g., Egert, 2015) or rather prefer another concept, such as a debt trajectory (Pescatori, Sandri and Simon, 2014) for the fact that countries with high, but decreasing debt-toGDP ratio seem to perform similar economic growth as their peers. The economies showing higher debt-to-GDP ratio therefore do not necessarily have smaller

\footnotetext{
${ }^{3}$ In spite of the fact that Ilzetzki, Mendoza and Vegh (2013), Auerbach and Gorodnichenko (2012) or Huidrom et al. (2019) do not explicitly refer to "fiscal space" and rather use a term "fiscal position", other authors reference to these studies as to those examining how fiscal space affects a size of the fiscal multipliers (see, e.g., reference of Kose et al. (2017) on Auerbach and Gorodnichenko (2012) or Huidrom et al. (2019)). We are aware of such simplification, however, to remain consistent with other authors, we use terms "fiscal position" and "fiscal space" interchangeably through paper.
} 
fiscal space. ${ }^{4}$ Moreover, different fiscal space variables can provide significantly different findings about fiscal space and one should not base conclusions on any single measure alone (see, Cheng and Pitterle, 2018), which calls for more comprehensive assessment of the fiscal space with regard to the size of the fiscal multipliers.

Fig u re 1

Fiscal Space Indicators (a Debt-to-GDP Ratio, Primary Balance as \% of GDP) in Selected Economies

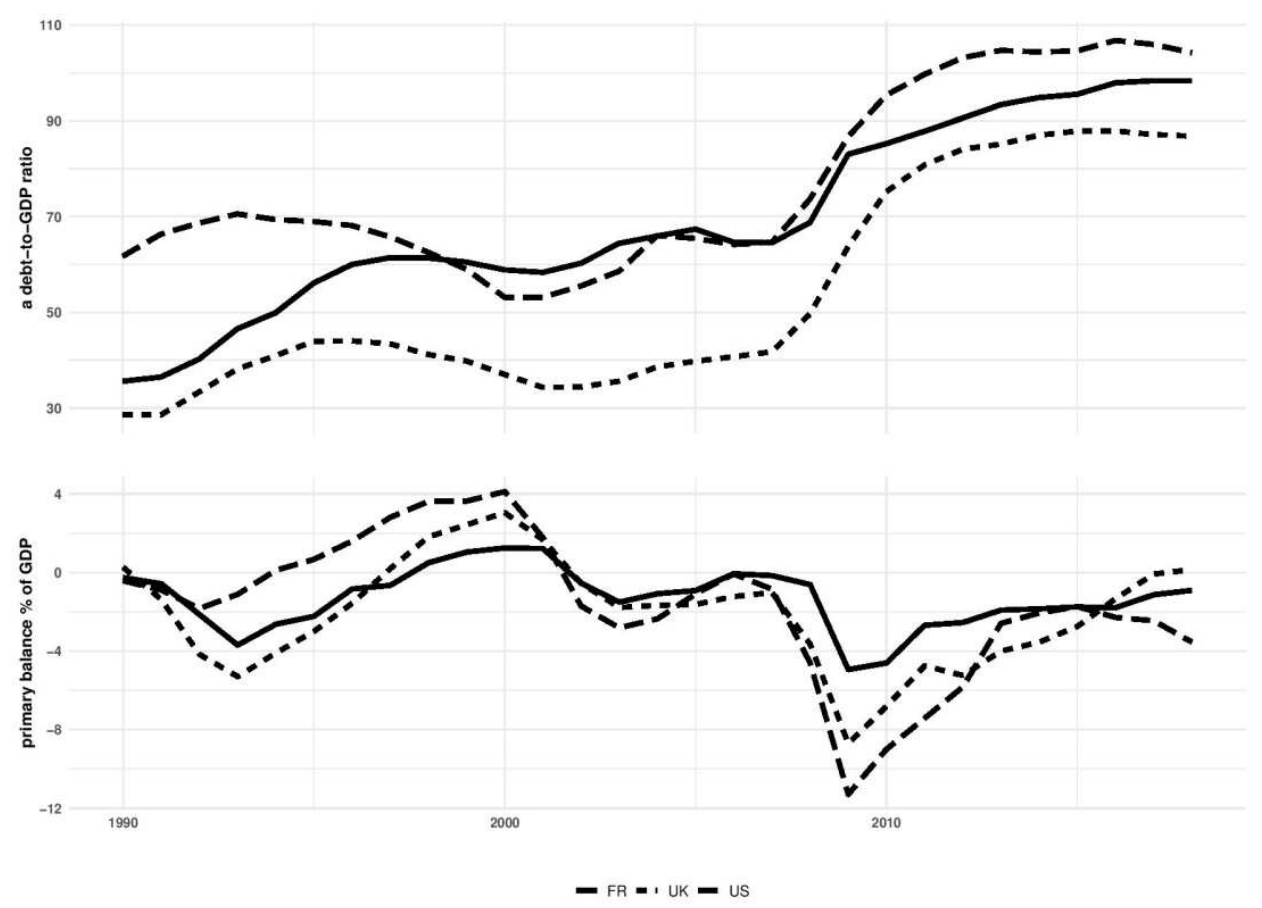

Source: Own elaboration based on data from Kose et al. (2017).

In this paper, we go beyond simple measure of solvency and follow Kose et al. (2017) by examining the primary balance as one of the indicators of a debt sustainability, by which we can get additional insight into the effects of fiscal policy (see Figure 1). The primary balance can be viewed as an indicator of current fiscal effort (Davis and Daniel, 1995), since interest payments - predetermined by a size of previous deficits - are not included. The aim of this study is to measure fiscal multipliers (both impact, as well as cumulative multipliers) with

\footnotetext{
${ }^{4}$ Such evidence is provided by Cheng and Pitterle (2018), who observe that some economies (e.g., Singapore or the United States) have larger fiscal space (measured as the ability-to-paymodel fiscal space) compared to others with lower debt-to-GDP ratio, which can be somewhat associated with their relatively optimistic economic outlook and institutional stability.
} 
regard to the size of the fiscal position defined as a primary fiscal balance in selected world's leading economies - the United States, the United Kingdom and France, which are at the same time economies with the highest external debt. ${ }^{5}$ Performing positive primary balance (or reducing primary balance deficit, respectively) is considered as crucial, especially for economies with excessive level of a debt, being essential for the reduction of their debt-to-GDP ratio (David and Daniel, 1995), which is valid for selected economies in the post-Great Recession period. ${ }^{6}$ Unlike traditional linear SVAR model, we estimate the threshold SVAR models (Tsay, 1998), by which we are able to count for potential effects of fiscal space on a size of the fiscal multipliers. Our results suggest that positive and negative shocks do not necessarily result in symmetric response of variables as smaller fiscal multipliers (i.e., less effective fiscal policies) are observed when economies show weaker fiscal position. While calculating a size of the impact spending multipliers, we find the impact spending multiplier in France as positive (0.35) in both regimes regardless of the shock sign, whereas the size of this multiplier in the United Kingdom is 0.30 and in the United States 0.39. Findings regarding this matter can be very valuable in setting optimal policy mix to revitalize the economy. This is crucial especially in the light of potential effects of recent austerity on the economic growth, which came as a response to emerging fiscal imbalances and increasing indebtedness of advanced economies.

The rest of this paper is structured as follows; in the next section, we describe our threshold SVAR methodology to measure fiscal multipliers in different fiscal regimes, including identification scheme, generalized impulse-response functions, fiscal multipliers and data description. Empirical results and discussion are provided in the second section, while the final section concludes our comments with policy recommendations.

\section{Threshold SVAR Methodology}

To study the effects of the fiscal policy shocks on the output depending on the fiscal position, we start with two-regime threshold VAR (TVAR) methodology. The two-regime TVAR model with threshold variable $z_{t-d}$ and delay $d$ can be defined as follows

\footnotetext{
${ }^{5}$ Gross external debt position, source: World Bank's Quarterly External Debt Statistics SDDS, $10 / 31 / 19$ update.

${ }^{6}$ It should be noted that literature on the relationship between the primary balance and the debt level underlines a slowing response of the primary balance to increasing level of debt; as debt increases, the primary balance tend to increase as well, however, the marginal response of the primary balance to debt seems to be stronger at moderate level of debt than at high level (see, e.g., Mendoza and Ostry, 2008).
} 


$$
Y_{t}=D_{1}(L) Y_{t-1} I\left[z_{t-d} \leq z^{*}\right]+D_{2}(L) Y_{t-1} I\left[z_{t-d}>\mathrm{z}^{*}\right]+u_{t}
$$

where $Y_{t}=\left(T_{t}, G_{t}, G D P_{t}\right)^{T}$ presents a vector of endogenous variables (net taxes, government spending and real output) and $u_{t}=\left(u_{t}^{T}, u_{t}^{G}, u_{t}^{G D P}\right)$ presents the vector of reduced form residuals. Subsequently, $I[$.$] represents an indicator function,$ which equals 1 if the condition holds and 0 otherwise. The threshold value $z^{*}$, together with the lag polynomial matrices $D_{1}(L)$ and $D_{2}(L)$ (including deterministic constant) have to be estimated. Threshold variable $z_{t-d}$ determines prevailing regime of the system, where the lag polynomial matrix can vary.

Following other studies, which measure fiscal multipliers in different business cycle phases (see, e.g., Baum and Koester, 2011; Batini, Callegari and Melina, 2012), we set the threshold delay parameter $d$ to 1 . The prevailing regime is determined by the threshold variable in the previous period. If the threshold variable $z$ at time $t-1$ exceeds the threshold value $z^{*}$, the variables at time $t$ are determined by the parameters of the upper regime and vice versa. In other words, it is assumed that the fiscal policy adjusts its behavior in a relatively short time after the regime switches as it is less likely to expect that the transitions between regimes would appear with a longer delay.

Each regime consists of the observations assigned to regime according to the threshold variable and selected threshold value $z^{*}$. Within each regime, the coefficients are estimated by the OLS method. This means that the TVAR model is linear in the parameters in each regime, but the switches from one regime to another are responsible for the non-linearity. Threshold value $z^{*}$ can be randomly selected - although, it needs to be empirically verified - or it is possible to apply conditional least squares estimation and select the model minimizing the residual sum of squares (Tsay, 1998).

To identify the VAR model, Cholesky decomposition of innovations can be used, which implies the contemporaneous interactions between exogenous shocks. Here, the endogenous variables are characterized by a Wald causal chain. Ordering of the endogenous variables then reflects expected particular economy structure, following general economic theory assumptions.

However, the lack of reasonable guidance for appropriate ordering led to the development of more sophisticated and flexible identification methods - i.e., the SVAR models. Compared to the first approach, identifying restrictions implemented in the SVAR models more precisely reflects theoretical assumptions about the economy structure. In the empirical studies examining fiscal policy, authors prefer to use the SVAR models, where the shock identification is based on Blanchard-Perotti identification scheme (Blanchard and Perotti, 2002). In this 
paper, we follow this approach, but we also check the robustness of the model by applying Cholesky decomposition.

Compared to the traditional VAR models, the TVAR model requires higher number of observations due to the independent estimation procedures of parameters in distinct regimes. Therefore, the main drawback of this method is that it requires high-frequency data (commonly used annual data are not sufficient in many cases). It is also a problem of short time series, which stands behind our decision to apply the TVAR model with only two regimes. ${ }^{7}$

\subsection{Identification Scheme}

While estimating linear, as well as non-linear model, researchers often face the problem of correlated reduced-form residuals; this means that the variancecovariance matrix of reduced-form residuals does not represent the identity matrix. Hence, the shock in one variable affects another variable at the same time. Following Blanchard and Perotti (2002), we assume that the reduced-form residuals are linear combinations of (structural) tax, government spending and the output shocks. More specifically, fiscal reduced-form residuals respond to unexpected structural fiscal policy shocks and the output shocks, which should reflect the activity of the automatic stabilizers. Output reduced-form residuals also respond to unexpected fiscal policy shocks, together with the structural shocks in the output. This can be defined by the following equations:

$$
\begin{aligned}
& u_{t}^{T}=a_{1} u_{t}^{G D P}+a_{2} \varepsilon_{t}^{G}+\varepsilon_{t}^{T} \\
& u_{t}^{G}=b_{1} u_{t}^{G D P}+b_{2} \varepsilon_{t}^{T}+\varepsilon_{t}^{G} \\
& u_{t}^{G D P}=c_{1} u_{t}^{T}+c_{2} u_{t}^{G}+\varepsilon_{t}^{G D P}
\end{aligned}
$$

where $\varepsilon_{t}=\left(\varepsilon_{t}^{T}, \varepsilon_{t}^{G}, \varepsilon_{t}^{G D P}\right)$ represents the vector of structural shocks. Eq. (2) denoting relations between the reduced-form residuals $u_{t}$ and the structural shocks $\varepsilon_{t}$ can be also re-written in the matrix notation:

$$
A u_{t}=B \varepsilon_{t}
$$

Similarly to study of Blanchard and Perotti (2002), the determination of parameters is carried out within three steps. ${ }^{8}$ In the first step, the parameters $a_{1}$ and $b_{1}$ are considered. We assume that parameters $a_{1}$ and $b_{1}$ represent the automatic

\footnotetext{
${ }^{7}$ Alternatively, it is possible to use a smooth transition VAR model for the estimation of the fiscal multipliers in narrow and wide fiscal space. Whereas dynamics of the variables in the TVAR approach is modeled by limited number of states, dynamics in smooth transition VAR is modeled by the continuum of states. As both approaches suit our needs, we choose the TVAR as our baseline model due to relative simplicity.
} 
effect of the output to fiscal variables and the discretionary reaction of fiscal policy to changes in output. The usage of quarterly data plays a key role in this case; as it is commonly known, the legislative process of democratic institutions takes a long time.

Therefore, the adoption of appropriate fiscal policy measure as a reaction to the unexpected output shocks takes more than one quarter, what makes a second effect irrelevant. Consequently, the parameters capture only the elasticity of net taxes and government spending to the output. Unlike Blanchard and Perotti (2002), we decide to calibrate the parameter $a_{1}$. Our decision about the selection of parameter $a_{1}$ in the United States and the United Kingdom is based on the work of Perotti (2004). Perotti (2004) sets the elasticity of government revenues for the United States and the United Kingdom to value 1.85 and 0.82 respectively. The elasticity coefficient for France is set to 1.00 based on work of Unal (2015). We assume that the components of government spending are not contemporaneously sensitive to changes in output, hence we set the elasticity of government spending to output (coefficient $b_{1}$ ) to 0 (Perotti, 2004). The second step includes the estimation of parameters $c_{1}$ and $c_{2}$. Given theparameters $a_{1}$ and $b_{1}$, we can calculate cyclically adjusted (CA) tax residuals as ${ }^{C A} u_{t}^{T}=u_{t}^{T}-a_{1} u_{t}^{G D P}$ and cyclically adjusted spending residuals as ${ }^{C A} u_{t}^{G}=u_{t}^{G}-b_{1} u_{t}^{G D P}=u_{t}^{G}$ (it results from the fact that $\left.b_{1}=0\right)$. Cyclically adjusted residuals are not correlated with $\varepsilon_{t}^{G D P}$, therefore they serve as instruments in the third partial equation of Eq. (2).

While estimating parameters $a_{2}$ and $b_{2}$, it is necessary to determine the character of fiscal policy. More specifically, it is necessary to take decision whether government spending reacts to changes in taxes $\left(a_{2}=0, b_{2} \neq 0\right)$ or taxes react to changes in government spending $\left(a_{2} \neq 0, b_{2}=0\right)$. Since it is difficult to find arguments that justify first or second ordering, we perform the OLS estimation between ${ }^{C A} u_{t}^{T}$ and ${ }^{C A} u_{t}^{G}$ with both types of orderings. ${ }^{9}$

\footnotetext{
${ }^{8}$ It should be noted that the SVAR models, particularly those using Blanchard-Perotti approach, have been criticized for several shortcomings (e.g., for the problem of fiscal foresight). The critique lies in the assumption that the structural shocks identified by this approach are interpreted as unanticipated changes. In fact, agents may have information on some fiscal policy measures before their implementation. Therefore, agents' decision is affected before the implementation of fiscal policy measure and shocks treated as unanticipated are in fact anticipated. Another shortcoming is the inability to capture purely exogenous shocks because revenue changes may result from asset and commodity price movements (Leigh et al., 2010). Nevertheless, this identification approach is heavily preferred choice in the fiscal VAR literature.

${ }^{9}$ Results presented in the next section are based on the second type of ordering. While changing the ordering, the spending multipliers remain robust. Although, the revenue multiplier seems to be higher for the regime of the narrow fiscal space.
} 
Given the relationship between reduced-form residuals and the structural shocks, we re-write the original TVAR model as

$$
A Y_{t}=C_{1}(L) Y_{t-1} I\left[z_{t-d} \leq z^{*}\right]+C_{2}(L) Y_{t-1} I\left[z_{t-d}>\mathrm{z}^{*}\right]+B \varepsilon_{t}
$$

where $D_{i}(L)=A^{-1} C_{i}(L)$ and $u_{t}=A^{-1} B \varepsilon_{t}$. We assume the shocks $\varepsilon_{t}$ are independent and identically distributed. $A$ describes the contemporaneous relations among the variables in the vector $Y_{t}$.

\subsection{Generalized Impulse Response Function}

Impulse response functions in the non-linear TVAR model cannot be easily generated from the model parameters as in the linear VAR models. To assess dynamics of the model, for which Wold representation does not exist, another method must be applied. Here, we follow the approach of Koop, Pesaran and Potter (1996) and generate generalized impulse response functions (GIRF), which allow us to evaluate the effects of fiscal shocks in the TVAR model. Due to the non-linearity of TVAR model, the reaction of variables to exogenous shock depends on the size and the sign of the shocks hitting the economy and the history of variables. The reaction of the variables in TVAR models to positive shock and the opposite reaction in case of negative shock need not be symmetric about the x-axis. The same holds for the size of the shock. A shock of size $2 \%$ does not have exactly twice the effect of a shock of size $1 \%$. As a result of large shock, the economy can move between the regimes differently in given periods than in the case of smaller shocks, therefore, it is essential to assess the effects of different shock size. Formally, the GIRF can be defined as

$$
\begin{aligned}
& \text { GIRF }=E\left[Y_{t+m} \mid \varepsilon_{t}, \varepsilon_{t+1}=0, \ldots, \varepsilon_{t+m}=0, \Omega_{t-1}\right]- \\
& -E\left[Y_{t+m} \mid \varepsilon_{t}=0, \varepsilon_{t+1}=0, \ldots, \varepsilon_{t+m}=0, \Omega_{t-1}\right]
\end{aligned}
$$

where $Y_{t+m}$ presents the vector of variables at time $t+m$ and $\Omega_{t-1}$ represents a history. It follows that GIRF is a difference between forecasted path of variable in an economy without shock and forecasted path of the same variable in an economy hit by a shock. To generate these GIRFs, numerical simulations are needed. ${ }^{10}$

\subsection{Fiscal Multipliers}

Once the shocks are identified, we can calculate the GIRFs and individual fiscal multipliers. Fiscal multiplier can be defined as a ratio of change in output $(\Delta y)$ to change in the fiscal variable represented by government spending $(\Delta g)$ or taxes $(-\Delta t)$. 
Following Spilimbergo, Symansky and Schindler (2009), we can calculate several types of the fiscal multipliers, depending on the time horizon. The impact multiplier can be defined as

$$
\frac{\Delta y_{t}}{\Delta g_{t}}
$$

which measures the immediate reaction of the output to change in the fiscal variable.

Subsequently, the cumulative multiplier defined as

$$
\frac{\sum_{j=0}^{N} \Delta y_{t+j}}{\sum_{j=0}^{N} \Delta g_{t+j}}
$$

captures the cumulative reaction of the output to cumulative change in the fiscal variable at some specific horizon $N$. This multiplier can be considered as the most appropriate measure among those mentioned in Spilimbergo, Symansky and Schindler (2009) due to broader implications.

From identified TVAR models, we compute GIRFs and the fiscal multipliers, which represent the effects of fiscal policy shocks (1\% and $2 \%$ shocks in the government spending and the government revenue) on the real output in both regimes (lower regime - narrow fiscal space, upper regime - wide fiscal space). Moreover, as the fiscal multipliers tend to be interpreted in units and not in percentages, we convert them into to the correct form using information on average share of net taxes and government spending on GDP in selected time period.

\subsection{Data}

The estimation of TVAR model requires at least twice as much observation as a regular VAR model. Therefore, we perform the estimation of TVAR model on countries with long and consistent quarterly data. To preserve the consistency, we do not interpolate data, neither combine various datasets. Suitable candidates, which meet given criteria, are selected world's leading economies with the highest external debt - France (FR), the United Kingdom (UK) and the United States (US).

\footnotetext{
${ }^{10}$ While generating the GIRFs, we simulate the evolution of variables using residuals (with and without initial shock) for each observation. The algorithm decides according to the value of threshold variable in the preceding forecasted period. This procedure calculates the next period simulated values of the variables along with a new value for the threshold variable. It follows that the threshold variable has a property of endogeneity, which allows transition between regimes as a result of the shock. In other words, threshold variable is not considered as an additional variable in the model, rather a difference of variables $T_{t}$ and $G_{t}$. Detailed algorithm is available in e.g., Ferraresi, Roventini and Fagiolo (2014).
} 
Net taxes are defined as total revenues less transfers, government spending consists of the sum of government consumption and government investments (see Table A6 in Appendix for variables definition and data sources). The difference between net taxes and government spending (plus interest payments) gives the value of fiscal balance as is reported by particular source. Since we exclude interest payments, the resulting difference represents primary fiscal balance. Variables are deflated by the output (GDP) deflator and seasonally adjusted using TRAMO/SEATS (if necessary).

Whereas several authors use the government debt-to-GDP ratio as a measure of the fiscal space (see, e.g., Ilzetzki, Mendoza and Vegh, 2013; Huidrom et al., 2019), we construct new variable of the fiscal space - primary fiscal balance as a difference between log value of net taxes and log value of government spending $(P B)$. However, stationarity tests indicate that primary fiscal balance is nonstationary in each country, therefore it cannot be in a given form considered as a threshold variable. Instead, we transform primary fiscal balance into the firstdifference form, which is further smoothened by 3-quarter moving average MA (3). ${ }^{11}$ Smoothening is a preferred and recommended transformation (see, e.g., Baum and Koester, 2011), when one wants to avoid frequent regime switches. Literature is ambiguous regarding the choice of the proper moving average setting. Therefore, we analyze the robustness of the results by applying MA (2) and MA (4) to differenced primary fiscal balance. Baseline model specification is based on the threshold variable smoothened by MA (3).

We estimate the TVAR model using variables in the first differences. But firstly, we apply logarithm to non-stationary series. We test whether the variables follow a random walk with drift, for which we use Augmented Dickey-Fuller (ADF) test, where the number of lags is chosen according to Schwarz information criterion (SIC). The ADF test indicates that all differenced series are stationary, so we can reject the null hypothesis of the unit root. The threshold variable is also assumed to be stationary, otherwise the system could permanently fall into one of the regimes. Results of the ADF test are summarized in Table 1.

Before we proceed to the estimation of TVAR model, the non-linearity test has to be conducted to find out whether the threshold-type non-linearity is present in the time series. Non-linearity test of Tsay (1998) serves that purpose. The test is based on the predictive residuals, which detect the threshold non-linearity.

\footnotetext{
${ }^{11}$ In other words, threshold variable presents a difference between growth rate of net taxes and growth rate of government spending. Each country has almost the same average ratio of net taxes and government spending to GDP. Moreover, differences between the ratio of net taxes and government spending to GDP in each period are not substantial so that it would be irrational to subtract those growth ratios in order to obtain changes in fiscal space. Average growth rate of net taxes exceeding average growth rate of government spending might indicate increased availability of sources for expenditure purposes.
} 
In line with the recommendation of Tsay (1998), we set the starting point of the recursive least squares estimation to be equal to $3 \sqrt{n}$, where $n$ presents the sample size. ${ }^{12}$

Table 1

ADF Test Results

\begin{tabular}{|c|c|c|c|c|c|}
\hline & $\mathbf{T}$ & $\mathbf{G}$ & $\mathbf{G D P}$ & $\mathbf{z}$ & PB \\
\hline FR & 0 & 0 & 0 & 6 & 0 \\
& $(-10.736 ;<0.001)$ & $(-15.019 ;<0.001)$ & $(-8.337 ;<0.001)$ & $(-4.039 ; 0.0017)$ & $(-2.420 ; 0.1389)$ \\
UK & 0 & 2 & 3 & 3 & 0 \\
& $(-13.054 ;<0.001)$ & $(-4.226 ; 0.0009)$ & $(-4.597 ; 0.0002)$ & $(-3.539 ; 0.0087)$ & $(-1.943 ; 0.3120)$ \\
US & 0 & 4 & 0 & 6 & 2 \\
& $(-12.814 ;<0.001)$ & $(-3.863 ; 0.0028)$ & $(-10.276 ;<0.001)$ & $(-4.556 ; 0.0002)$ & $(-2.630 ; 0.0888)$ \\
\hline
\end{tabular}

Note: We provide a number of lags. T-statistics and p-values are in parentheses.

Source: Own calculations based on data from Eurostat and Bureau of Economic Analysis.

Table 2

Non-linearity Test Results

\begin{tabular}{|l|c|c|c|}
\hline & MA (3) & MA (4) & MA (2) \\
\hline FR & $24.737(0.016)$ & $21.659(0.042)$ & $20.438(0.059)$ \\
UK & $48.534(0.000)$ & $44.937(0.000)$ & $53.608(0.000)$ \\
US & $70.041(0.000)$ & $63.573(0.000)$ & $54.318(0.000)$ \\
\hline
\end{tabular}

Note: We provide test statistic. P-values are in parentheses.

Source: Own calculations based on data from Eurostat and Bureau of Economic Analysis.

If the Tsay test indicates the presence of the non-linearity in the system, the estimation of the TVAR model can be carried out. Non-linearity test results are summarized in Table 2. In addition to the test results for threshold variable smoothened by MA (3), Table 2 also contains results for different smoothing settings. The test rejects hypothesis of linearity at the $5 \%$ level in all cases, except for the MA (2) variant of threshold variable for France. We should bear it in mind during the result interpretation.

\section{Results and Discussion}

\subsection{Threshold SVAR Estimation Results}

Compared to linear models, the issue of the optimal lag selection is more complicated in the non-linear framework. The decision on the number of lags in our models was based on Schwarz information criterion (SIC), which recommends

\footnotetext{
${ }^{12}$ As recommended by Tsay (1998), test is conducted with various trimming values and we rejected the null hypothesis at least at the $10 \%$ significance level.
} 
the optimal number of lags for all three countries as 1 . Since we have limited number of observations for each country, one lag seems to be understandable selection.

T a ble 3

Threshold SVAR Estimation

\begin{tabular}{|l|c|c|c|}
\hline & Data sample & No. of lags & No. of observations in lower/upper regime \\
\hline FR & $1980 Q 1-2016 Q 3$ & 1 & $93 / 50$ \\
UK & $1987 Q 1-2016 Q 3$ & 1 & $32 / 83$ \\
US & $1964 Q 1-2016 Q 4$ & 1 & $46 / 162$ \\
\hline
\end{tabular}

Note: Lower regime denotes narrow fiscal space, whereas upper regime denotes wide fiscal space (in terms of primary fiscal balance).

Source: Own calculations based on data from Eurostat and Bureau of Economic Analysis.

Results regarding the threshold SVAR model estimations and particular number of observations in lower and upper regime, which represent narrow and wide fiscal space, are provided in Table $3 .{ }^{13}$

The regime of narrow fiscal space in case of the United Kingdom and the United States consists of relatively small number of observations (less than $30 \%$ in both countries). This might suggest that nonlinear behavior in the form of regime switch arises in a small number of cases when fiscal policy has highly limited fiscal space.

As we have already mentioned, all examined countries show a high level of a debt-to-GDP ratio, which can constrain fiscal space in some ways. Although, the situation of the United States and the United Kingdom might not be so critical compared to France as these economies can benefit from strong market financing access. It might be also partly explained by having a status of a reserve currency (e.g., status of the US dollar). In case of France, observations seem to be relatively similarly distributed within both regimes, hence narrow fiscal space is more frequently present than in the United States or the United Kingdom (more than 65\% of observations are in the lower regime - narrow fiscal space). France therefore seems to have a limited space for adjusting fiscal policy to respond to shocks; in recent years, France mostly showed a high level of deficit (above 3\% of GDP), which was also a reason for France to be a subject of the Excessive Deficit Procedure defined by the Treaty on the Functioning of the European Union. ${ }^{14}$

To evaluate the effects of fiscal shocks in the threshold SVAR models, we calculate the GIRFs, by which we can observe responses of the fiscal variables (output, particularly) to \pm 1 percentage point government spending and revenue

\footnotetext{
${ }^{13}$ Detailed results regarding the threshold variable $\mathrm{z}^{*}$ are available upon request.

${ }^{14}$ The excessive deficit situation in France has been corrected in 2018. The United Kingdom was also a subject of this procedure, whereas it has been corrected in 2017.
} 
shocks in observed economies - France, the United Kingdom and the United States (see Figure 2, 3 and 4, respectively).

Figure 2

\section{GIRFs - France}
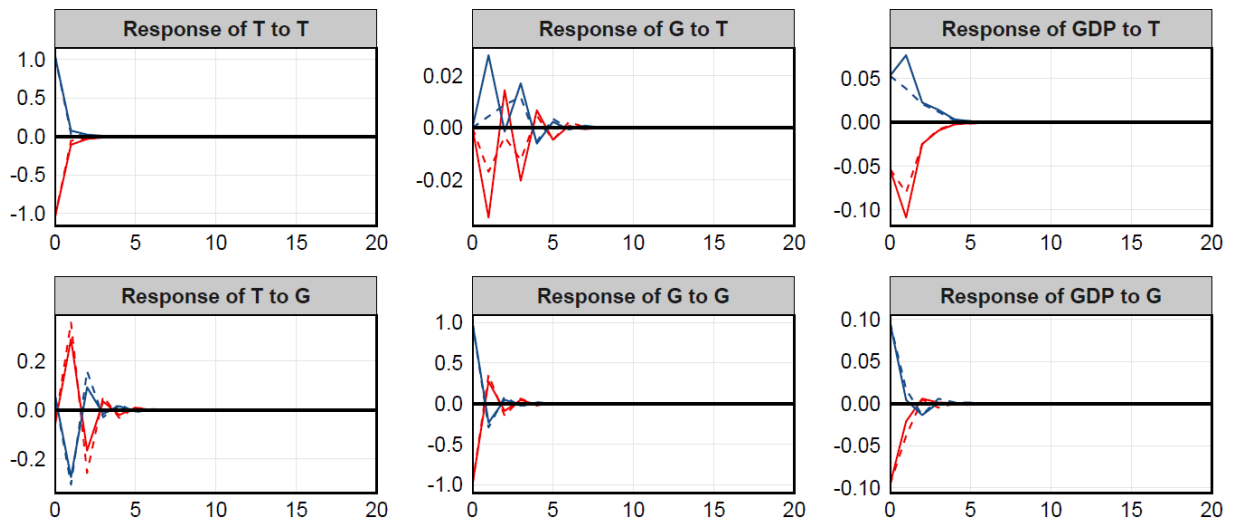

$\square-1 \%$ shock - Narrow fiscal space $---1 \%$ shock - Wide fiscal space $\square+1 \%$ shock - Narrow fiscal space $--+1 \%$ shock - Wide fiscal space

Source: Own calculations based on data from Eurostat and Bureau of Economic Analysis.

Our results suggest that positive and negative shocks do not necessarily result in symmetric response of variables, which supports the justification of this model. Reaction of output to 1 percentage point positive shock in government spending (response of GDP to G) tends to be higher in times of wide fiscal space and lower in times of narrow fiscal space in all analyzed countries.

Figure 3

\section{GIRFs - the United Kingdom}
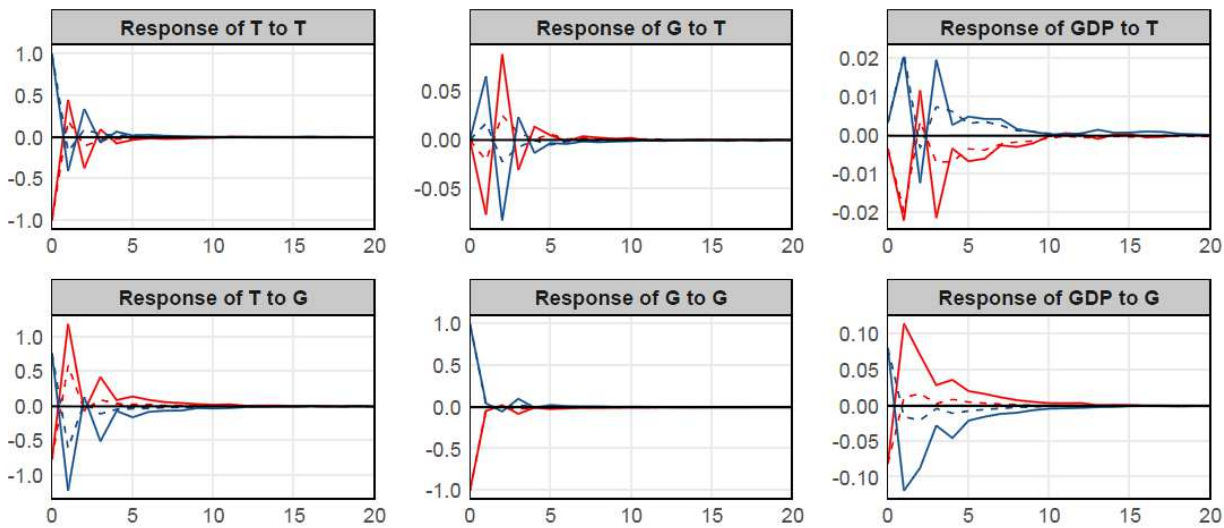

$-1 \%$ shock - Narrow fiscal space - - $-1 \%$ shock - Wide fiscal space $-+1 \%$ shock - Narrow fiscal space $--+1 \%$ shock - Wide fiscal space

Source: Own calculations based on data from Eurostat and Bureau of Economic Analysis. 
Therefore, smaller fiscal multipliers (i.e., less effective fiscal policies) are observed when economies show weaker fiscal position, having our findings are in line with Ilzetzki, Mendoza and Vegh (2013) or Huidrom et al. (2019), in spite of the fact that these studies use a debt-to-GDP ratio as a measure of the fiscal space.

Figure 4

\section{GIRFs - the United States}
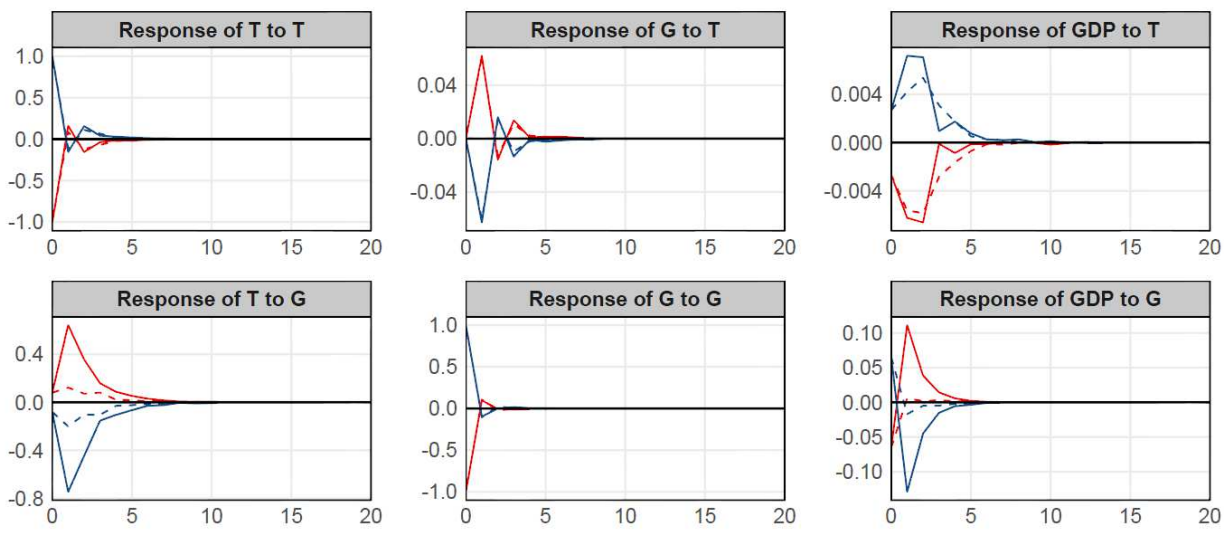

$-1 \%$ shock - Narrow fiscal space - - $-1 \%$ shock - Wide fiscal space $-+1 \%$ shock - Narrow fiscal space $--+1 \%$ shock - Wide fiscal space

Source: Own calculations based on data from Eurostat and Bureau of Economic Analysis.

On the other hand, reaction of output to 1 percentage point positive shock in net taxes (response of GDP to T) is lower in the regime of wide fiscal space than in regime of narrow fiscal space. ${ }^{15}$ However, the situation in the UK (Figure 3) and the US (Figure 4) is reversed when the economy is hit by negative shock in net taxes. ${ }^{16}$ In spite of the fact that negative revenue multipliers are not in line with theory expectations, similar results appear relatively often in the empirical literature. For instance, Perotti (2004) finds negative revenue multiplier in the US economy during examined period $1960-2001$. Analogous evidence is provided for the United Kingdom. Furthermore, Perotti (2004) observes downward trend in revenue (as well as spending) multipliers across countries after 1979. There is likewise evidence of negative revenue multiplier in France regardless of the phase of the business cycle (see, e.g., Baum and Koester, 2011).

\footnotetext{
${ }^{15}$ Even though positive reaction of GDP to a revenue increase does not seem intuitive, it can be explained by the crowding-out effect of public spending and the crowding-in effect of public revenues, whereas the consumption and investment increase after the shock as a result of fiscal consolidation, which moves the economy from an unsustainable fiscal path to a sustainable one (see, e.g., Giavazzi, Jappelli and Pagano, 2000; Afonso and Sousa, 2009; Perotti, 2004 for detailed discussion on this matter).

${ }^{16}$ We observe a rather oscillatory behavior in the GIRF's for the UK; the reason may lie in the order of the MA model further discussed in the robustness check analysis or smaller number of cases when fiscal policy has highly limited fiscal space which we mentioned earlier in the text.
} 
While calculating a size of the impact spending multipliers, results do not seem substantially different for all examined countries; whereas impact spending multiplier in France is positive (0.35) in both regimes regardless of the shock sign, the size of this multiplier in the United Kingdom is 0.30 and in the United States 0.39. Corresponding cumulative fiscal (both spending as well as revenue) multipliers are reported in Table 4.

Table 4

Cumulative Fiscal Multipliers

\begin{tabular}{|l|l|r|r|r|r|}
\hline \multirow{2}{*}{} & & \multicolumn{2}{|c|}{ 2 quarters } & \multicolumn{2}{c|}{ 6 quarters } \\
\cline { 3 - 6 } & & $\begin{array}{c}1 \%(-1 \%) \\
\text { spending shock }\end{array}$ & $\begin{array}{c}1 \%(-1 \%) \\
\text { revenue shock }\end{array}$ & $\begin{array}{c}1 \%(-1 \%) \\
\text { spending shock }\end{array}$ & $\begin{array}{c}1 \%(-1 \%) \\
\text { revenue shock }\end{array}$ \\
\hline \multirow{2}{*}{ FR } & Lower regime & $0.392(0.500)$ & $-0.501(-0.590)$ & $0.410(0.510)$ & $-0.560(-0.620)$ \\
& Upper regime & $0.459(0.600)$ & $-0.391(-0.530)$ & $0.510(0.660)$ & $-0.447(-0.560)$ \\
UK & Lower regime & $-0.574(-0.472)$ & $-0.060(-0.070)$ & $-0.946(-0.834)$ & $-0.215(-0.262)$ \\
& Upper regime & $0.206(0.235)$ & $-0.113(-0.104)$ & $0.083(0.134)$ & $-0.200(-0.193)$ \\
& Lower regime & $-0.711(-0.552)$ & $-0.100(-0.100)$ & $-0.844(-0.683)$ & $-0.115(-0.100)$ \\
& Upper regime & $0.282(0.330)$ & $-0.075(-0.080)$ & $0.225(0.333)$ & $-0.099(-0.100)$ \\
\hline
\end{tabular}

Source: Own calculations based on data from Eurostat and Bureau of Economic Analysis.

Estimated fiscal multipliers, particularly spending multipliers, are in line with theory expectations. Indeed, expansionary fiscal policy in times of narrow fiscal space dampens expansionary effects on real economic activity. While comparing spending and revenue multipliers, we mainly find lower revenue than spending multipliers, confirming Keynesian theory. While authors do not find substantial differences between spending and revenue multipliers in case of emerging economies (Ilzetzki, Mendoza and Vegh, 2013), studies focusing on developed economies provide evidence that revenue multipliers tend to be lower than spending multipliers (see, e.g., Mineshima, Poplawski-Ribeiro and Weber, 2014), which is in accordance with Keynesian theory since tax cuts are considered as less effective tools to stimulate the economy compared to the rise in government spending.

For all examined countries, we observe cumulative multipliers below 1. Studies investigating a size of the fiscal multipliers often provide various results. For instance, whereas Nakamura and Steinsson (2014) suggest substantial effects of the government spending shocks on the output (multiplier above 1) in the US, Dupor and Guerrero (2017) find lower multiplier effect (between 0 and 0.5) for the same economy, which is similar to our results.

\subsection{Further Results and Robustness Check}

To check the robustness of our results, we decide to check whether the results remain valid for i) alternative moving average settings, ii) structural shocks identified with Cholesky decomposition replacing Blanchard-Perotti identification 
approach, and finally, iii) alternative threshold value. Following robustness analysis proves that spending multipliers remain robust, yet the same is not unambiguous for the revenue multipliers in the UK and the US.

Firstly, we need to clarify whether the results are sensitive to moving average variants, which are often arbitrarily selected in similar studies. As we could not reject the hypothesis of linearity in the nonlinearity test for France, we cannot take into account the MA (2) variant of the threshold variable as relevant in this particular case. Nevertheless, we report corresponding GIRFs for France. Figure A1 in Appendix captures the output response to fiscal shocks for threshold variable smoothened by MA (2), whereas Figure A2 captures similar situation for the MA (4) variant. Except for France, (MA (2) variant), the results for spending multipliers remain qualitatively similar and robust. Revenue multipliers seem to be higher in the regime of narrow fiscal space in France and the US, however, the situation is reversed for the UK's revenue multipliers if the threshold variable is smoothened by the MA (4). Moreover, the impact revenue multipliers in the UK and the US are higher (and positive) in the MA (2) variant.

Due to previously mentioned criticism of Blanchard-Perotti identification approach, it is recommended to check the sensitivity of the output dynamics with altered assumptions regarding the shocks identification. Alternatively, fiscal VAR studies tend to rely on Cholesky decomposition (Batini, Callegari and Melina, 2012), which on the other hand, suffers from the problem of proper variables ordering. Therefore, we firstly estimate the TVAR model with unaltered ordering (see Figure A3 in the Appendix) and after that, reorder the variables (see Figure A4 in the Appendix) into the form $Y_{t}=\left(G_{t}, G D P_{t}, T_{t}\right)^{T}$ as in Batini, Callegari and Melina (2012). Reordering reveals following relations among examined variables; government spending and net taxes do not respond contemporaneously to the output shocks, however, the response of the output to fiscal shocks is immediate. While considering the structure of net taxes, which involves the components acting as automatic stabilizers, no contemporaneous reaction of net taxes to the output shocks seems to be unlikely. Hence in the latter case, net taxes immediately react to the output shocks, although the output is not contemporaneously affected by the shocks in net taxes. Government spending contemporaneously affects the output, but not vice versa. Neither the first nor the second ordering affects the output movements to the extent that it would switch cumulative response between regimes. Output reaction to government spending shock remains robust in all countries. In case of France, the output response to the shock in net taxes remains robust, too. While reordering variables (see Figure A4 in the Appendix), the output reaction to shock in net taxes is significantly altered. Whereas the reaction was immediate in the baseline model, here it is delayed by one period. 
Finally, we assess how a value of the threshold affects the unexpected reaction of the output to fiscal shocks. More specifically, we set a threshold value to 0 . This splits our sample into two approximately equal parts. Figure A5 in Appendix captures the response of the output to fiscal shocks. The output response to the shock in government spending is qualitatively similar in all three countries. Cumulative spending multipliers are still higher in the regime of the wide fiscal space compared to the narrow fiscal space. However, the difference between regimes in the case of US is no longer so striking. There is evident adjustment in the spending multiplier for the regime of narrow fiscal space. Uniform redistribution of observations shifts cumulative spending multiplier from the negative values to positive. In case of France, the response of the output to net taxes remains roughly unchanged, confirming robustness. In the case of UK, there is slightly higher revenue multiplier in the regime of narrow fiscal space. In case of the US, the revenue multiplier in the narrow fiscal space initially exceeds revenue multiplier in the wide fiscal space (regardless of the shock sign), but few periods later, the dynamics is changed.

\section{Conclusions}

The knowledge of a size of the fiscal multipliers presents one of the key elements for the proper fiscal policy implementation. As empirical literature regarding this matter suggests, the size of the fiscal multipliers might be conditioned on various factors. Whereas conjectural factors (i.e., the business cycle phases) have been a subject to numerous studies, the aim of this paper was to focus on one of the less investigated structural factors, which might affect the country's response to the fiscal shocks - a size of the fiscal space.

Using threshold SVAR methodology, we measure a size of the fiscal multipliers in three selected world's leading economies. The results suggest that lower fiscal multipliers are associated with narrower fiscal space. Even though our proxy variable of the fiscal space is defined as a primary fiscal balance, findings are in line with previous studies (e.g., Ilzetzki, Mendoza and Vegh, 2013 or Huidrom et al., 2019), which use a level of debt-to-GDP ratio. Hence, policymakers should bear in mind that a size of the fiscal space matters for the financial stability and the effectiveness of implemented fiscal policy (in terms of the size of the fiscal multipliers) and ensure a sufficient fiscal space in order to provide more effective fiscal policy. Fiscal austerity plays a crucial role in this case as a response to emerging fiscal imbalances and increasing indebtedness of advanced economies as well. At the same time, we mostly find lower fiscal revenue multipliers compared to fiscal spending multipliers, by which we confirm Keynesian theory, 
according to which a rise in government spending is considered as more effective tool to stimulate the economy in contrast to the tax cuts.

To support our findings, we also provide a robustness analysis with different scenarios; a size of the spending multipliers remains qualitatively similar and robust, even though we do not find unambiguous results for the revenue multipliers in the UK and the US. Thus, this topic might require further analysis. Further research using threshold SVAR methodology might be also focused on other structural factors (i.e., trade openness, tax revenue administration, and others) or other measures of fiscal space, which could provide more comprehensive view on this issue.

\section{References}

AFONSO, A. - SOUSA, R. M. (2009): The Macroeconomic Effects of Fiscal Policy. [ECB Working Paper Series, No. 991.] Frankfurt am Main: European Central Bank.

AUERBACH, A. J. - GORODNICHENKO, Y. (2012): Measuring the Output Responses to Fiscal Policy. American Economic Journal: Economic Policy, 4, No. 2, pp. 1 - 27.

BARRO, R. J. - REDLICK, C. J. (2011): Macroeconomic Effects from Government Purchases and Taxes. Quarterly Journal of Economics, 126, No. 1, pp. $51-102$.

BATINI, N. - CALlEGARI, G. - MELINA, G. (2012): Successful Austerity in the United States, Europe and Japan. [IMF Working Papers, No. WP/12/190.] Washington, DC: International Monetary Fund.

BAUM, A. - KOESTER, G. B. (2011): The Impact of Fiscal Policy on Economic Activity over the Business Cycle - Evidence from a Threshold VAR Analysis. [Discussion Paper Series 1: Economic Studies, No. 2011/03.] Berlin: Deutsche Bundesbank.

BLANCHARD, O. - PEROTTI, R. (2002): An Empirical Characterization of the Dynamic Effects of Changes in Government Spending and Taxes on Output. Quarterly Journal of Economics, 117, No. 4, pp. $1329-1368$.

COELHO, M. (2019): Fiscal Stimulus in a Monetary Union: Evidence from Eurozone Regions. IMF Economic Review, 67, No. 3, pp. $573-617$.

CORSETTI, G. - MEIER, A. - MULLER, G. J. (2012): What Determines Government Spending Multipliers? [IMF Working Paper, No. WP/12/150.] Washington, DC: International Monetary Fund.

DAVIS, J. M. - DANIEL, J. (1995): Guidelines for Fiscal Adjustment. [Pamphlet Series, No. 49.] Washington, DC: International Monetary Fund.

DUPOR, B. - GUERRERO, R. (2017): Local and Aggregate Fiscal Policy Multipliers. Journal of Monetary Economics, 92, No. C, pp. $16-30$.

EGERT, B. (2015): Public Debt, Economic Growth and Nonlinear Effects: Myth or Reality? Journal of Macroeconomics, 43, No. C, pp. $226-238$.

FERRARESI, T. - ROVENTINI, A. - FAGIOLO, G. (2014): Fiscal Policies and Credit Regimes: A TVAR Approach. Journal of Applied Econometrics, 30, No. 7, pp. 1047 - 1072.

GIAVAZZI, F. - JAPPELLI, T. - PAGANO, M. (2000): Searching for Non-Linear Effects of Fiscal Policy: Evidence from Industrial and Developing Countries. European Economic Review, 44, No. 7, pp. $1259-1289$.

HUIDROM, R. - KOSE, M. A. - LIM, J. J. - OHNSORGE, F. L. (2019): Why Do Fiscal Multipliers Depend on Fiscal Positions? Journal of Monetary Economics, 114, pp. 109 - 125. 
CHENG, H. W. J. - PITTERLE, I. (2018): Towards a More Comprehensive Assessment of Fiscal Space. [DESA Working Paper, No. 153.] New York: United Nations.

ILZETZKI, E. - MENDOZA, E. G. - VEGH, C. A. (2013): How Big (Small) Are Fiscal Multipliers? Journal of Monetary Economics, 60, No. 2, pp. 239 - 254.

KOOP, G. M. - PESARAN, H. - POTTER, S. M. (1996): Impulse Response Analysis in NonLinear Multivariate Models. Journal of Econometrics, 74, No. 1, pp. 119 - 147.

KOSE, M. A. - KURLAT, S. - OHNSORGE, F. - SUGAWARA, N. (2017): A Cross-Country Database of Fiscal Space. [Policy Research Working Paper, No. 8157.] Washington, DC: The World Bank.

LEIGH, D. - DEVRIES, P, FREEDMAN, C. - GUAJARDO, J. - LAXTON, D. - PESCATORI, A. (2010): Will It Hurt? Macroeconomic Effects of Fiscal Consolidation. [IMF World Economic Outlook, Chapter 3.] Washington, DC: International Monetary Fund.

LEY, E. (2009): Fiscal Policy for Growth. [PREM Notes Economic Policy, No. 131.] Washington, DC: The World Bank.

MENDOZA, E. G. - OSTRY, J. D. (2008): International Evidence on Fiscal Solvency: Is Fiscal Policy 'Responsible'? Journal of Monetary Economics, 55, No. 6, pp. $1081-1093$.

MINESHIMA, A. - POPLAWSKI-RIBEIRO, M. - WEBER, A. (2014): Fiscal Multipliers. In: COTTARELli, C., GERSON, P. and SENHADJI, A. (eds): Post-Crisis Fiscal Policy. Cambridge: MIT Press, pp. 676.

NAKAMURA, E. - STEINSSON, J. (2014): Fiscal Stimulus in a Monetary Union: Evidence from US Regions. American Economic Review, 104, No. 3, pp. 753 - 792.

PEROTTI, R. (1999): Fiscal Policy in Good Times and Bad. Quarterly Journal of Economics, 114, No. 4 , pp. $1399-1436$.

PEROTTI, R. (2004): Estimating the Effects of Fiscal Policy in OECD Countries. [IGIER Working Paper, No. 276.] Milan: Bocconi University.

PESCATORI, A. - SANDRI, D. - SIMON, J. (2014): Debt and Growth: Is There a Magic Threshold? [IMF Working Paper, No. 14/34.] Washington, DC: International Monetary Fund.

REINHART, C. M. - ROGOFF, K. S. (2010): Growth in a Time of Debt. American Economic Review, 100, No. 2, pp. $573-578$.

SPILIMBERGO, A. - SYMANSKY, S. - SCHINDLER, M. (2009): Fiscal Multipliers. [IMF Staff Position Note, SPN/09/11.] Washington: International Monetary Fund.

TSAY, R. S. (1998): Testing and Modeling Multivariate Threshold Models. Journal of the American Statistical Association, 93, No. 443, pp. 1188 - 1202.

UNAL, U. (2015): Rethinking the Effects of Fiscal Policy on Macroeconomic Aggregates: A Disaggregated SVAR Analysis. Journal for Economic Forecasting, 18, No. 3, pp. 120 - 135. 


\section{Appendix}

Figure A1

Output Response to Fiscal Shocks (threshold value smoothened by MA (2))
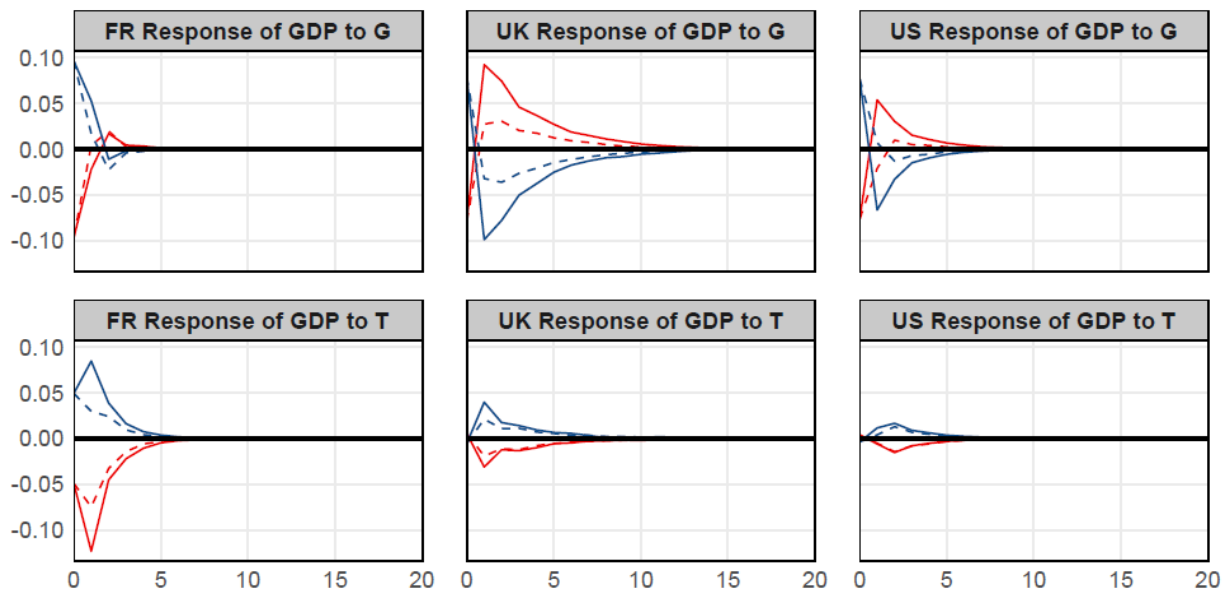

$\square-1 \%$ shock - Narrow fiscal space $---1 \%$ shock - Wide fiscal space $\square+1 \%$ shock - Narrow fiscal space $--+1 \%$ shock - Wide fiscal space

Source: Own calculations based on data from Eurostat and Bureau of Economic Analysis.

Figure A2

Output Response to Fiscal Shocks (threshold value smoothened by MA (4))
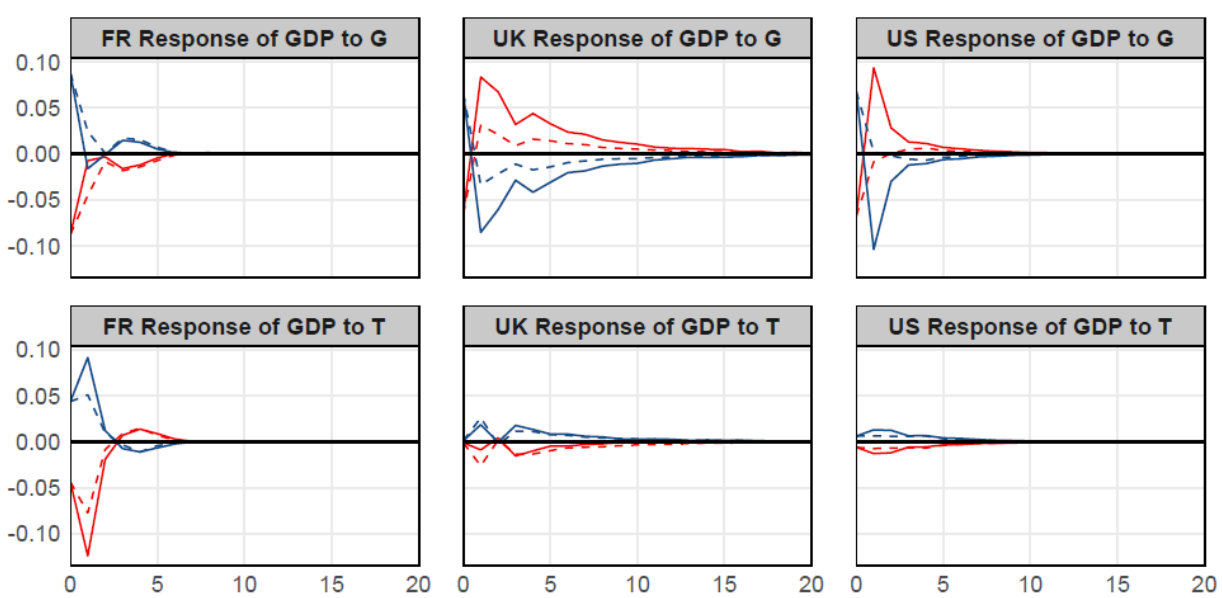

$\square-1 \%$ shock - Narrow fiscal space - - - $1 \%$ shock - Wide fiscal space $\square+1 \%$ shock - Narrow fiscal space $--+1 \%$ shock - Wide fiscal space

Source: Own calculations based on data from Eurostat and Bureau of Economic Analysis. 
Figure A3

Output Response to Fiscal Shocks (Cholesky decomposition - ordering T, G, GDP)
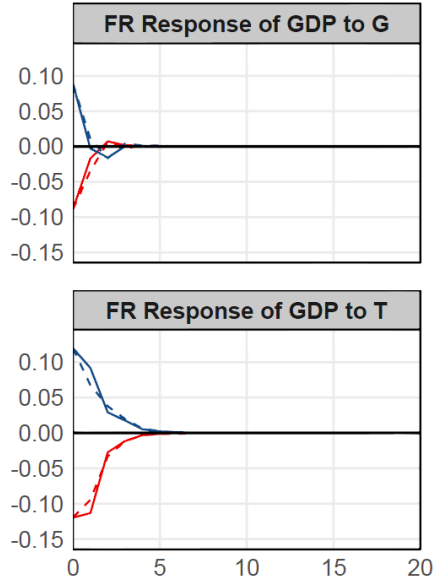

- $-1 \%$ shock - Narrow fiscal space -

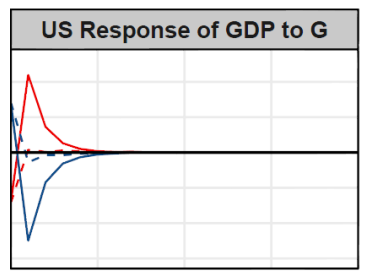

UK Response of GDP to T
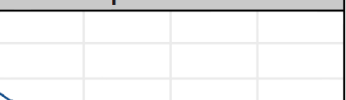

cे
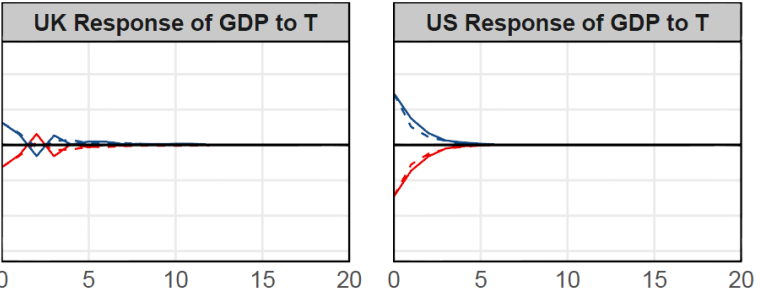

Source: Own calculations based on data from Eurostat and Bureau of Economic Analysis.

Figure A4

Output Response to Fiscal Shocks (Cholesky decomposition - ordering G, GDP, T)
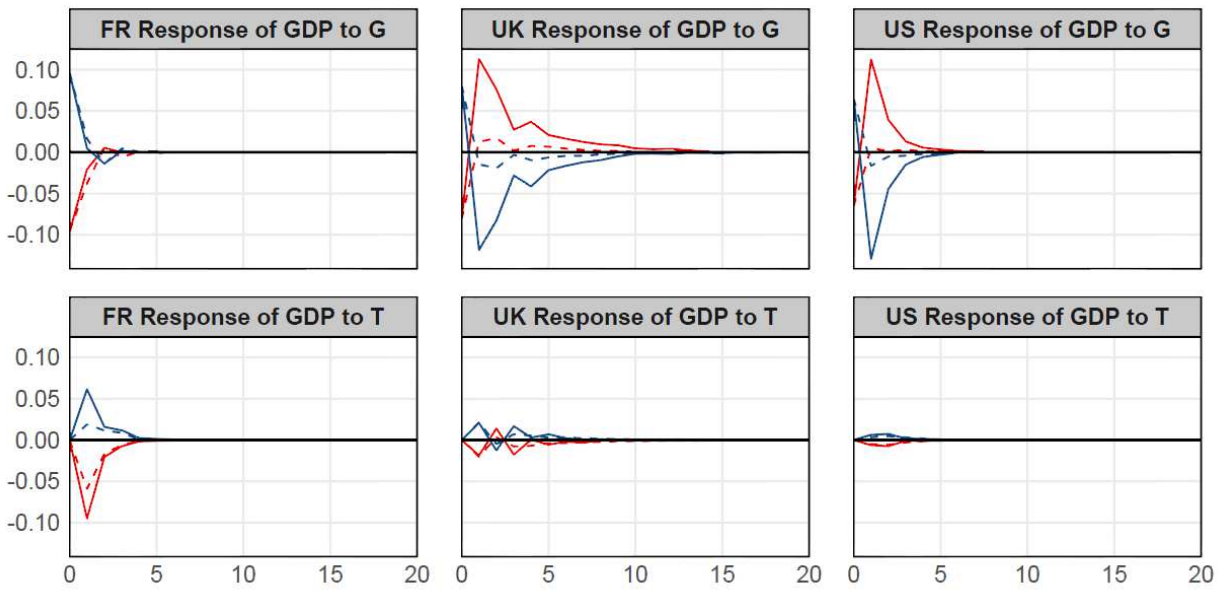

$--1 \%$ shock - Narrow fiscal space - - - $1 \%$ shock - Wide fiscal space $-++1 \%$ shock - Narrow fiscal space $--+1 \%$ shock - Wide fiscal space

Source: Own calculations based on data from Eurostat and Bureau of Economic Analysis. 


\section{Figure A5}

Output Response to Fiscal Shocks $\left(z^{*}=0\right)$
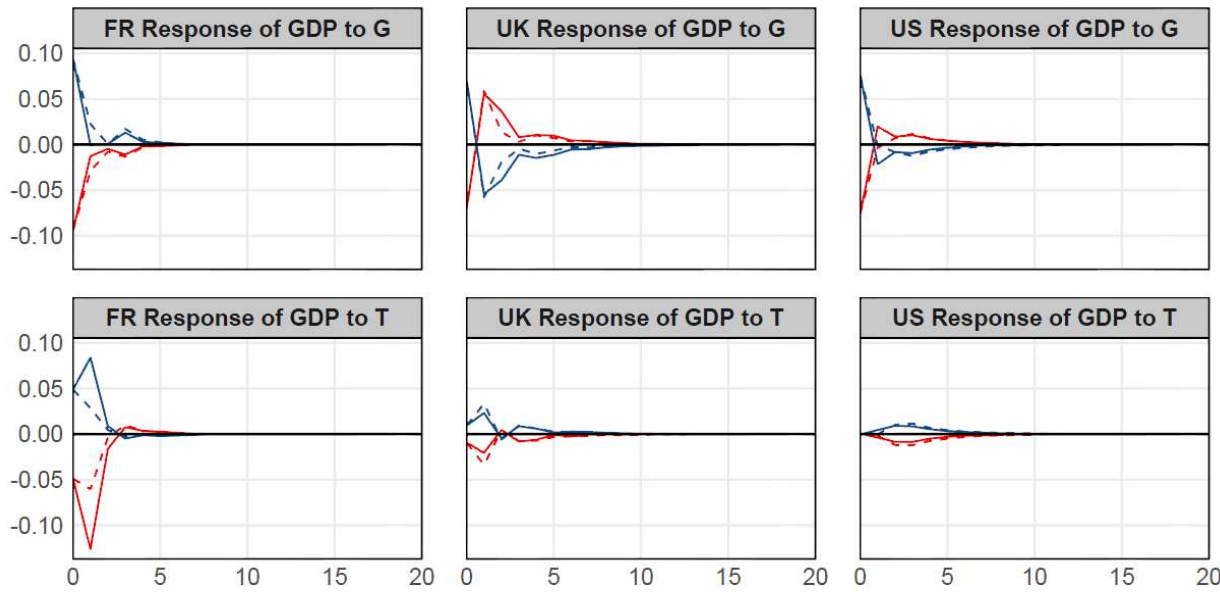

$-1 \%$ shock - Narrow fiscal space $---1 \%$ shock - Wide fiscal space $\square+1 \%$ shock - Narrow fiscal space $--+1 \%$ shock - Wide fiscal space

Source: Own calculations based on data from Eurostat and Bureau of Economic Analysis. 


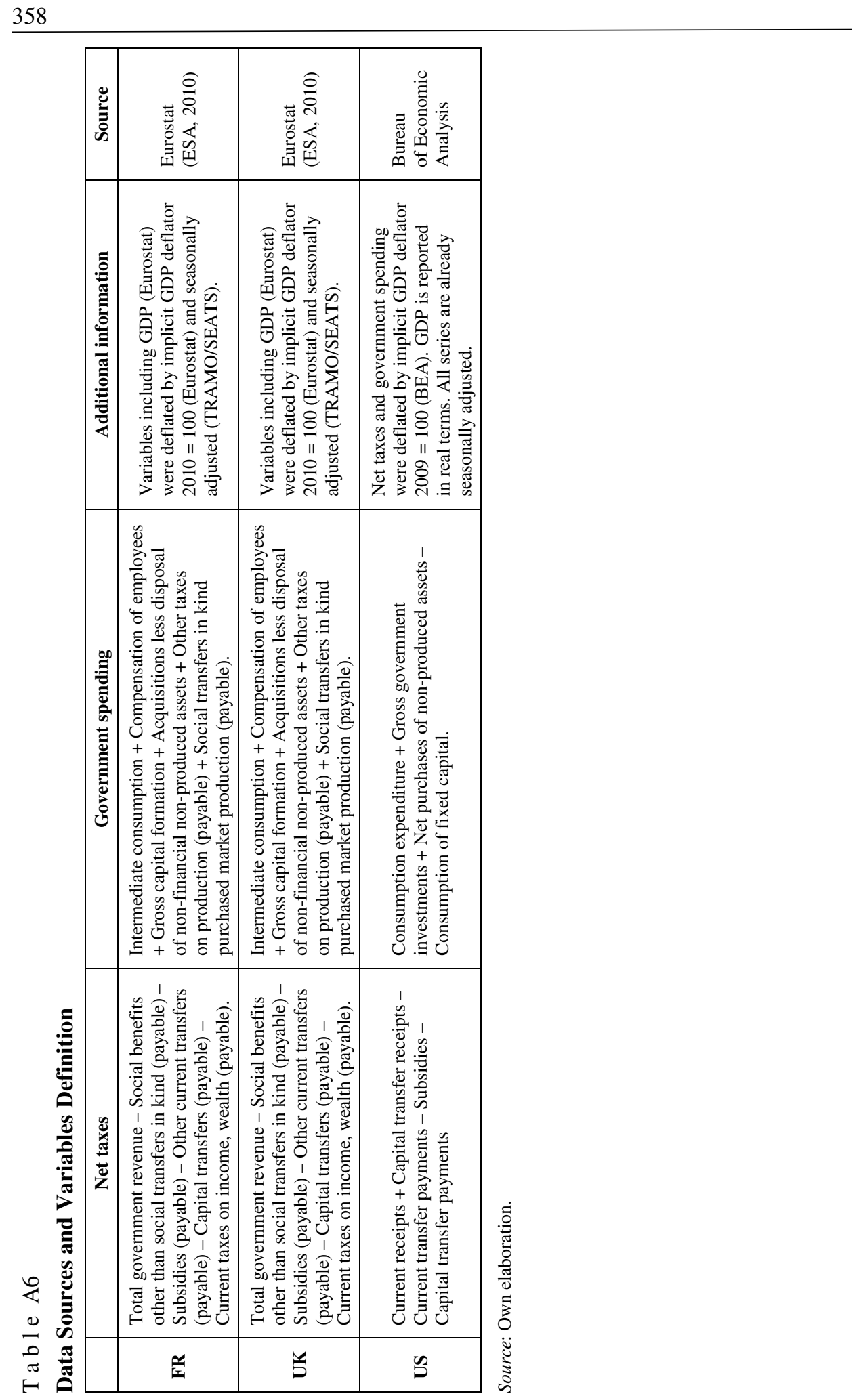

